\title{
Simultaneous determination of multiclass emerging contaminants in aquatic plants by ultrasound-assisted matrix solid-phase dispersion and GC-MS
}

\author{
Ramón Aznar • Beatriz Albero • Consuelo Sánchez-Brunete • Esther Miguel • \\ Isabel Martín-Girela • José L. Tadeo
}

\begin{abstract}
A multiresidue method was developed for the simultaneous determination of 31 emerging contaminants (pharmaceutical compounds, hormones, personal care products, biocides, and flame retardants) in aquatic plants. Analytes were extracted by ultrasound-assisted matrix solidphase dispersion (UA-MSPD) and determined by gas chromatography-mass spectrometry after sylilation, The method was validated for different aquatic plants (Typha angustifolia, Arundo donax, and Lemna minor) and a semiaquatic cultivated plant (Oryza sativa) with good recoveries at concentrations of 100 and $25 \mathrm{ng} \mathrm{g}^{-1}$ wet weight, ranging from 70 to $120 \%$, and low method detection limits $(0.3$ to $2.2 \mathrm{ng} \mathrm{g}^{-1}$ wet weight). A significant difference of the chromatographic response was observed for some compounds in neat solvent versus matrix extracts, and therefore, quantification was carried out using matrix-matched standards in order to overcome this matrix effect. Aquatic plants taken from rivers located at three Spanish regions were analyzed, and the compounds detected were parabens, bisphenol A, benzophenone-3, cyfluthrin, and cypermethrin. The levels found ranged from 6 to $25 \mathrm{ng} \mathrm{g}^{-1}$ wet weight except for cypermethrin that was detected at $235 \mathrm{ng} \mathrm{g}^{-1}$ wet weight in $O$. sativa samples.
\end{abstract}

Keywords Aquatic plants · Ultrasound-assisted matrix solid-phase dispersion · GC-MS · Emerging contaminants . Typha angustifolia $\cdot$ Oryza sativa $\cdot$ Pharmaceuticals $\cdot$ Biocides

\section{Introduction}

Emerging contaminants (ECs) have raised concern among the scientific community because of their ubiquitous presence in different environmental compartments (Aznar et al. 2014a; Wu et al. 2011; Bell et al. 2013; Wang et al. 2012) and the risk they may pose to the environment and human health, taking also into account their potential bioaccumulation in animals (Corcellas et al. 2015; Ortiz de Garcia et al. 2013; Wu et al. 2012) and uptake by plants (Tanoue et al. 2012), which are routes for entering the food chain (CalderonPreciado et al. 2011; Rodil et al. 2012; Goldstein et al. 2014).

ECs (pharmaceuticals, personal care products, flame retardants, and biocides) are widely used and can reach the environment through effluent waters and the use of biosolids ( $\mathrm{Al}$ Aukidy et al. 2012; Albero et al. 2012) or manure (Aznar et al. 2014a) applied to improve agricultural soils. Nevertheless, their continuous release through septic system effluents (Kinney et al. 2006) and discharge of wastewater treatment plants (WWTPs), after being inefficiently removed by conventional methods, are the main routes to reach different environmental compartments (Thomas and Foster 2005; Harada et al. 2008). Thus, ECs can be considered pseudo persistent, reaching the environment uninterruptedly and making them a priority to the scientific community.

Among biocide substances, synthetic pyrethroids (PYs), derived from chrysanthemic acid, are widely used indoors to control household insects, such as mosquitoes, termites, and other harmful insects, in place of more toxic organophosphorus and organochlorine insecticides. Indeed, they are much 
more effective against a wide spectrum of pests than organochlorines and organophosphates and, consequently, they are used in many applications. However, several pyrethroids are known to affect the central nervous system of humans and to have endocrine-disrupting effects (Kohler and Triebskorn 2013). Moreover, PYs may have a negative impact on the environment, primarily on water bodies, due to their toxicity to arthropods (Wang et al. 2012; Weston et al. 2005; Song et al. 2015) and their bioaccumulation potential in fish (Corcellas et al. 2015). There are several processes involved in the contamination mitigation, such as hydrolysis, photolysis, adsorption, microbial degradation, and plant uptake. Several authors have addressed the ability of plants to uptake and translocate organic contaminants (Tanoue et al. 2012; Calderon-Preciado et al. 2011; Wu et al. 2013; Herklotz et al. 2010). Thus, aquatic plants, which are continuously exposed to organic contaminants transported by water, may be used as bioindicators of the occurrence of these contaminants in freshwater as well as for phytoremediation. Dordio et al. (2011a, b) showed that constructed wetland treatment of wastewaters showed removal efficiencies of 96,97 , and $75 \%$ for ibuprofen, carbamazepine, and clofibric acid, respectively. Reinhold et al. (2010) reported on constructed treatment wetlands and demonstrated that they have the potential to reclaim wastewaters through the removal of trace concentrations of emerging organic pollutants, including personal care products, pharmaceuticals, and pesticides. These studies demonstrated that aquatic plants contributed both directly and indirectly to the aqueous depletion of emerging organic pollutants through both active and passive processes.

Multiresidue analyses of the organic pollutants in plants are limited by the complexity of the matrix and the properties of the analytes, requiring powerful and selective techniques such as gas chromatography (GC) coupled to mass spectrometry (MS) (Bisceglia et al. 2010; Niewiadowska et al. 2010) or LC-MS (Matamoros et al. 2012). GC-MS is a robust and less expensive technique generally available in most analytical laboratories, but the presence of polar functional groups with active hydrogens in some of the compounds studied requires the use of a derivatization procedure to reduce their polarity and enhance their volatility before GC analysis. Several authors have pointed out a gap of multiresidue methods for ECs in plants (Matamoros et al. 2012) and no multiresidue method has been found for the simultaneous analysis of multiclass ECs commonly found in freshwater, including pharmaceuticals, personal care products, flame retardants, and pyrethroids in aquatic plants.

Therefore, the aim of this study was to develop an analytical method, based on ultrasound-assisted matrix solid-phase dispersion (UA-MSPD) and gas chromatography-mass spectrometry (GC-MS), for the simultaneous determination of 31 organic pollutants (pharmaceuticals, personal care products, hormones, flame retardants, and biocides) in aquatic plants
(Typha angustifolia, Arundo donax, Oryza sativa, and Lemna minor) and evaluate their presence in plants taken from three rivers in different Spanish regions.

\section{Material and methods}

\section{Standards and reagents}

Standards of bifenthrin, fenpropathrin, $\lambda$-cyhalothrin, permethrin, cyfluthrin, $\alpha$-cypermethrin, $\tau$-fluvalinate, esfenvalerate, deltamethrin, triclosan, and methyl triclosan (purity $>99 \%$ ) were supplied by Riedel-de Haën (Seelze, Germany). Standards of estrone, hexestrol, diethylstilbestrol, ibuprofen, gemfibrozil, fenoprofen, naproxen, mefenamic acid, ketoprofen, carbamazepine, fenofibrate, nonylphenol, bisphenol A (BPA), benzophenone-3 (BP3), 2,2',4,4'-tetrabromodiphenyl ether (BDE-47), 2,2',4,4',6-pentabromodiphenyl ether (BDE-100), methyl paraben and propyl paraben (purity $>97 \%$ ) were purchased from Sigma-Aldrich (St Louis, MO, USA). Tris(2-carboxyethyl) phosphine (TCEP) and tris(2-chloroisopropyl) phosphate (TCPP) were obtained from Dr. Ehrenstorfer (Augsburg, Germany). All target compounds are shown in Table 1.

Ethyl acetate (EtAc), acetonitrile (ACN), residue analysis grade, ammonium hydroxide $\left(\mathrm{NH}_{4} \mathrm{OH}\right) \geq 32 \%$, Silica Bondesil-C18, particle diameter of $40 \mu \mathrm{m}$, and primary secondary amine (PSA) (Bondesil-PSA, $40 \mu \mathrm{m}$ ) were purchased from Varian (Palo Alto, CA, USA). Enviro-Clean Bulk Chlorofiltr was acquired from Carlo Erba (Madrid, Spain). Graphitized carbon black (GCB) (Supelclean ENVI-Carb 120/400) was purchased from Supelco (Madrid, Spain). The derivatization agent $N$-(tert-butyldimethylsilyl)- $N$-methyltrifluoroacetamide (MTBSTFA, purity $\geq 95 \%$ ) with $1 \%$ tertbutyldimethylchlorosilane (TBDMCS) and formic acid were obtained from Sigma-Aldrich (St Louis, MO, USA). Florisil, 150-250 $\mu \mathrm{m}$ (60-100 mesh), was supplied by Aldrich (Steinheim, Germany). Magnesium sulfate anhydrous $\left(\mathrm{MgSO}_{4}\right)$ was purchased from Merck (Darmstadt, Germany).

Separate stock solutions of individual compounds were made up at $50 \mu \mathrm{g} \mathrm{mL}^{-1}$ in $\mathrm{ACN}$ and stored at $-18^{\circ} \mathrm{C}$. A mixed stock solution of $1 \mu \mathrm{g} \mathrm{mL}^{-1}$ containing all analytes was prepared by dilution with $\mathrm{ACN}$ of the individual stock solutions. A working mixture solution at $500 \mathrm{ng} \mathrm{mL}^{-1}$ was prepared weekly by dilution with $\mathrm{ACN}$ of the mixed stock solution. All solutions were stored in the darkness at $4{ }^{\circ} \mathrm{C}$ up to 8 weeks.

\section{Plant material}

Samples of T. angustifolia, A. donax, and L. minor were provided by the School of Agricultural Engineering, Polytechnic University of Madrid, Spain. $O$. sativa was taken from the natural park of Albufera (Valencia, Spain) within an area 
Table 1 Physicochemical properties, retention times $\left(t_{\mathrm{R}}, \min \right)$, and selected ions $(\mathrm{m} / \mathrm{z})$ of the compounds studied

\begin{tabular}{|c|c|c|c|c|c|c|}
\hline \multirow[t]{2}{*}{ Name } & \multicolumn{2}{|c|}{ Physicochemical properties ${ }^{\mathrm{a}}$} & \multicolumn{4}{|c|}{ SIM parameters } \\
\hline & $\log K_{\text {ow }}$ & pka & $t_{\mathrm{R}}$ & $T$ & $Q 1$ & $Q 2$ \\
\hline Methyl paraben & 1.7 & 8.2 & 11.27 & 209 & 210 & 266 \\
\hline TCEP & 1.6 & - & 11.38 & 249 & 250 & 63 \\
\hline TCPP & 2.6 & - & 11.57 & 125 & 99 & 277 \\
\hline Ibuprofen & 4 & 4.5 & 11.85 & 263 & 264 & 117 \\
\hline Propyl paraben & 2.7 & 8.4 & 12.15 & 237 & 238 & 294 \\
\hline Methyl triclosan & 5.2 & - & 13.38 & 302 & 304 & 252 \\
\hline Nonylphenol & 3.8 & 10.7 & 13.38 & 334 & 277 & 278 \\
\hline Gemfibrozil & 4.7 & 4.4 & 13.45 & 243 & 179 & 307 \\
\hline Fenoprofen & 3.9 & 4.2 & 13.68 & 299 & 197 & 206 \\
\hline $\mathrm{BP} 3$ & 3.7 & 7.6 & 14.11 & 285 & 242 & 286 \\
\hline Naproxen & 3.2 & 4.8 & 14.13 & 287 & 185 & 288 \\
\hline Triclosan & 4.8 & 8 & 14.34 & 347 & 345 & 200 \\
\hline Mefenamic acid & 5.1 & 4.2 & 14.64 & 298 & 224 & 355 \\
\hline Ketoprofen & 3.1 & 4.5 & 14.65 & 311 & 295 & 105 \\
\hline Bifenthrin & 6 & - & 14.8 & 181 & 165 & 166 \\
\hline Fenpropathrin & 6 & - & 14.87 & 125 & 181 & 265 \\
\hline Carbamazepine & 2.5 & 13.9 & 14.95 & 193 & 194 & 293 \\
\hline BDE-47 & 8.8 & - & 15.16 & 486 & 326 & 488 \\
\hline Fenofibrate & 4.8 & -4.9 & 15.19 & 121 & 273 & 139 \\
\hline$\lambda$-Cyhalothrin & 6.9 & - & 15.24 & 197 & 181 & 208 \\
\hline Permethrin & 6.5 & - & 15.74 & 183 & 163 & 165 \\
\hline BPA & 3.4 & 9 & 15.7 & 441 & 442 & 456 \\
\hline BDE-100 & 8.9 & - & 15.92 & 404 & 406 & 566 \\
\hline Cyfluthrin & 5.9 & - & 16.06 & 163 & 206 & 226 \\
\hline Hexestrol & 4.8 & 9.9 & 16.35 & 249 & 250 & 337 \\
\hline$\alpha$-Cypermethrin & 6.6 & - & 16.41 & 163 & 165 & 181 \\
\hline Diethylstilbestrol & 5.1 & - & 16.5 & 496 & 497 & 498 \\
\hline$\tau$-Fluvalinate & 4.3 & - & 17.09 & 250 & 252 & 181 \\
\hline Estrone & 3.1 & 10.3 & 17.1 & 327 & 384 & 328 \\
\hline Esfenvalerate & 4 & - & 17.2 & 125 & 167 & 181 \\
\hline Deltamethrin & 6.1 & - & 17.74 & 181 & 253 & 251 \\
\hline
\end{tabular}

$T$ target ion, $Q 1$ and $Q 2$ qualifier ions

${ }^{\text {a }}$ Data compiled from previous studies: (Aznar et al. 2014b; Bhandari et al. 2009; Oros and Werner 2005)

irrigated with pure artesian water. Plants were maintained in darkness at $4{ }^{\circ} \mathrm{C}$ and transported to the laboratory where representative portions of the aerial part of the selected plants were ground using a food processor and kept at $20^{\circ} \mathrm{C}$ until analyses. These samples, after preliminary screenings, did not show any of the target compounds included in this work and they were used as blanks. T. angustifolia was employed in the optimization of the method because it was the most complex matrix.

The validated method was applied to plants taken from rivers located at different Spanish regions (Valencia, Madrid, and Andalucía) during a sampling campaign carried out in summer 2015 to assess the presence of pollutants.

\section{Sample preparation}

\section{Ultrasound-assisted matrix solid-phase dispersion}

UA-MSPD was performed mixing $1 \mathrm{~g}$ of aquatic plant with $4 \mathrm{~g}$ of Florisil and $2 \mathrm{~g}$ of $\mathrm{MgSO}_{4}$ in a glass mortar. Then the mixture was blended with a glass pestle for $5 \mathrm{~min}$ to yield a homogeneous material and placed in a $20-\mathrm{mL}$ glass column (10 $\mathrm{cm} \times 20 \mathrm{~mm}$ i.d., from Becton-Dickinson, Madrid, Spain) over two paper filters (Whatman No. 1 paper circles of 2-cm diameter, Maidstone, $\mathrm{UK}$ ) at the end with $2 \mathrm{~g}$ of $\mathrm{MgSO}_{4}$. EtAc with $3 \% \mathrm{NH}_{4} \mathrm{OH}(8 \mathrm{~mL})$ was added to each column and $2 \mathrm{~mL}$ was used to wash the mortar and pestle. Columns were sonicated for $15 \mathrm{~min}$ in an ultrasonic water bath (Raypa, Barcelona, Spain) at room temperature. The water level in the bath was adjusted to equal the extraction solvent level inside the columns, which were supported upright in a tube rack and closed with one-way stopcocks. Then extracts were collected in tubes using a multiport vacuum manifold (Supelco, Visiprep, Madrid) and evaporated near dryness. The extraction was repeated twice with $5 \mathrm{~mL}$ ACN containing $4 \%$ formic acid to ensure the complete extraction of the acidic target compounds. The extract was evaporated to $1 \mathrm{~mL}$ using a Genevac EZ-2 evaporator (purchased from NET Interlab, Spain) before the cleanup step.

\section{Cleanup}

Aquatic plant extracts $(1 \mathrm{~mL})$ were cleaned through a $5-\mathrm{mL}$ glass column (Normax, Lisbon, Portugal) with two paper filters (Whatman No. 1, Maidstone, UK) containing $1 \mathrm{~g}$ of $\mathrm{MgSO}_{4}$ and $1 \mathrm{~g}$ of C18. Analytes were eluted with $5 \mathrm{~mL}$ of $\mathrm{ACN}$ and extracts were collected in tubes using a multiport vacuum manifold, evaporated to dryness, and reconstituted to $0.5 \mathrm{~mL}$ with ACN before their derivatization.

\section{Derivatization}

Prior to the GC-MS determination, some of the studied analytes need to be derivatized to increase their volatility. The derivation agent MTBSTFA:TBDMCS $(99: 1, v / v)$ was selected, as it presents the best performance for pharmaceutical and personal care products in comparison with other derivatization agents (Schummer et al. 2009). Thus, the $t$-butyldimethylsilyl derivatives were prepared by the addition of $50 \mu \mathrm{L}$ of MTBSTFA:TBDMCS $(99: 1, v / v)$ to an aliquot $(100 \mu \mathrm{L})$ of the plant extract and transferred into a 2-mL reaction vial with a micro insert. Vials were closed and the mixture was left to react for $1 \mathrm{~h}$ at $70{ }^{\circ} \mathrm{C}$ before the GC-MS analysis. 


\section{Detection equipment}

Gas chromatography-mass spectrometry (GC-MS) analysis was performed with an Agilent 6890 (Waldbronn, Germany) gas chromatograph equipped with an automatic injector and a mass spectrometric detector, model HP 5977A. A fused silica capillary column ZB-5MS, $5 \%$ phenyl polysiloxane as nonpolar stationary phase ( $30 \mathrm{~m} \times 0.25 \mathrm{~mm}$ i.d. and $0.25-\mu \mathrm{m}$ film thickness), from Phenomenex (Torrance, CA), was used for the analysis.

Operating conditions were in solvent-vent mode as follows: $2 \mu \mathrm{L}$ of plant extracts were injected in a simple-taper glass liner with a nominal volume of $800 \mu \mathrm{L}$ with glass wool. The split vent was open for $0.1 \mathrm{~min}$ with an inlet pressure of

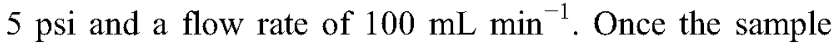
introduction was completed, the inlet was switched to splitless mode for analyte transfer. After $2.6 \mathrm{~min}$, the purge value was activated at a $60 \mathrm{~mL} \min ^{-1}$ flow rate. Helium (purity $99.995 \%$ ) was used as carrier gas at a constant flow rate of $1.2 \mathrm{~mL} \mathrm{~min}^{-1}$. The temperature program of the oven started at $50{ }^{\circ} \mathrm{C}$, kept for $0.1 \mathrm{~min}$, then ramped to $300^{\circ} \mathrm{C}$ at $600{ }^{\circ} \mathrm{C} \mathrm{min}^{-1}$, held $5 \mathrm{~min}$, and finally decreased to the initial temperature cooling with compressed air. The column temperature was maintained at $50^{\circ} \mathrm{C}$ for $2.6 \mathrm{~min}$, then programmed

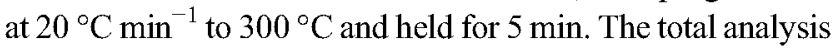
time was $20.1 \mathrm{~min}$ and the equilibration time was $4 \mathrm{~min}$.

The mass spectrometric detector was operated in electron impact ionization mode with an ionizing energy of $70 \mathrm{eV}$, an ion source temperature of $230^{\circ} \mathrm{C}$, and a quadrupole temperature of $150^{\circ} \mathrm{C}$. The electron multiplier voltage was set with a gain factor of 4 and a solvent delay of $10.5 \mathrm{~min}$ was used. Table 1 lists the compounds with their retention times and selected ions to be used in SIM mode. The target and qualifier abundances were determined by injection of standards under the same chromatographic conditions using full scan with the mass/charge ratio ranging from 50 to $550 \mathrm{~m} / \mathrm{z}$. The compounds were confirmed by their retention times, the identification of target and qualifier ions, and the determination of qualifier to target ratios. Retention times must be within $\pm 0.1 \mathrm{~min}$ of the expected time and qualifier-to-target ratios within a $20 \%$ range for positive confirmation. The quantification was accomplished by matrix-matched calibration.

\section{Method validation}

In order to evaluate the method developed for the detection of ECs in aquatic plants, different quality parameters were studied: recoveries, precision, linearity, and sensitivity.

Plants were spiked with the analytes at two levels (25 and $100 \mathrm{ng} \mathrm{g}^{-1}$ ) with four sample replicates, to study the recoveries and the accuracy of the method. The precision of the method was evaluated in terms of repeatability (intra-day precision) and reproducibility (inter-day precision) at 100 and $25 \mathrm{ng} \mathrm{g}^{-1}$. The repeatability was assessed by the application of the whole procedure on the same day, and the reproducibility was evaluated performing the complete procedure in different days. The results were expressed as \%RSD (six replicates).

To evaluate the sensitivity, method detection limit (MDL) and limit of quantification (LOQ) of the developed method were determined using ten replicates of plant extracts, spiked at $2.5 \mathrm{ng} \mathrm{g}^{-1}$. The equation to calculate the MDL was the following: $\mathrm{MDL}=t_{99} \times S$, where $t_{99}$ is the Student value for a $99 \%$ confidence level and $n-1$ degrees of freedom and $S$ is the standard deviation of the replicate analyses. The LOQ was calculated as 10 times the standard deviation of the results of the replicate analysis used to determine MDL.

Finally, to evaluate linearity and matrix effect, two sets of calibration solutions were prepared in the range from 1 to $400 \mathrm{ng} \mathrm{g}^{-1}$; one set was solvent-based and the other was prepared spiking blank plant extracts at the same concentrations. There are several approaches to counteract matrix-induced effects, but due to the high price and the nonexistence of internal standards for some of the 31 organic pollutants studied, matrixmatched calibration was selected (Aznar et al. 2014b).

In order to reduce possible memory effects of the column, prior to the analysis of samples, the inlet was flushed by heating at $300{ }^{\circ} \mathrm{C}$ for $30 \mathrm{~min}$ and one laboratory blank was run with each set of samples to check for memory effects and demonstrate laboratory background levels.

\section{Statistical analysis}

Standard statistical analyses were carried out to study the significant differences of the method using STATGRAPHIC CENTURION. One-way ANOVA was applied to determine significant differences at a $p \leq 0.01$ level.

\section{Results and discussion}

\section{Solvent selection}

In the first assay, $1 \mathrm{~g}$ of $T$. angustifolia spiked at $100 \mathrm{ng} \mathrm{g}^{-1}$ was placed in a mortar and blended with $4 \mathrm{~g}$ of Florisil and $2 \mathrm{~g}$ of $\mathrm{MgSO}_{4}$. Different organic solvents and combination of them changing the $\mathrm{pH}$ were tested to evaluate extraction yields. Figure 1 shows the recoveries obtained with different extraction solvents for a representative selection of the studied compounds. Firstly, two extractions with ACN did not present good recoveries, particularly for the acidic compounds (i.e., mefenamic acid, data not shown). Thus, the $\mathrm{pH}$ of the second extraction was changed (adding $3 \%$ of formic acid), and the recoveries of those compounds clearly improved. In order to improve the extraction yields of the target analytes, particularly the more lipophilic compounds, such as pyrethroids and the brominated flame retardants (BDE-47 and BDE-100), a less polar solvent was selected to perform the first step of the 
Fig. 1 Solvent selection using Typha angustifolia spiked at $100 \mathrm{ng} \mathrm{g}^{-1}$. Different letters indicate significant differences $(p \leq 0.01)$

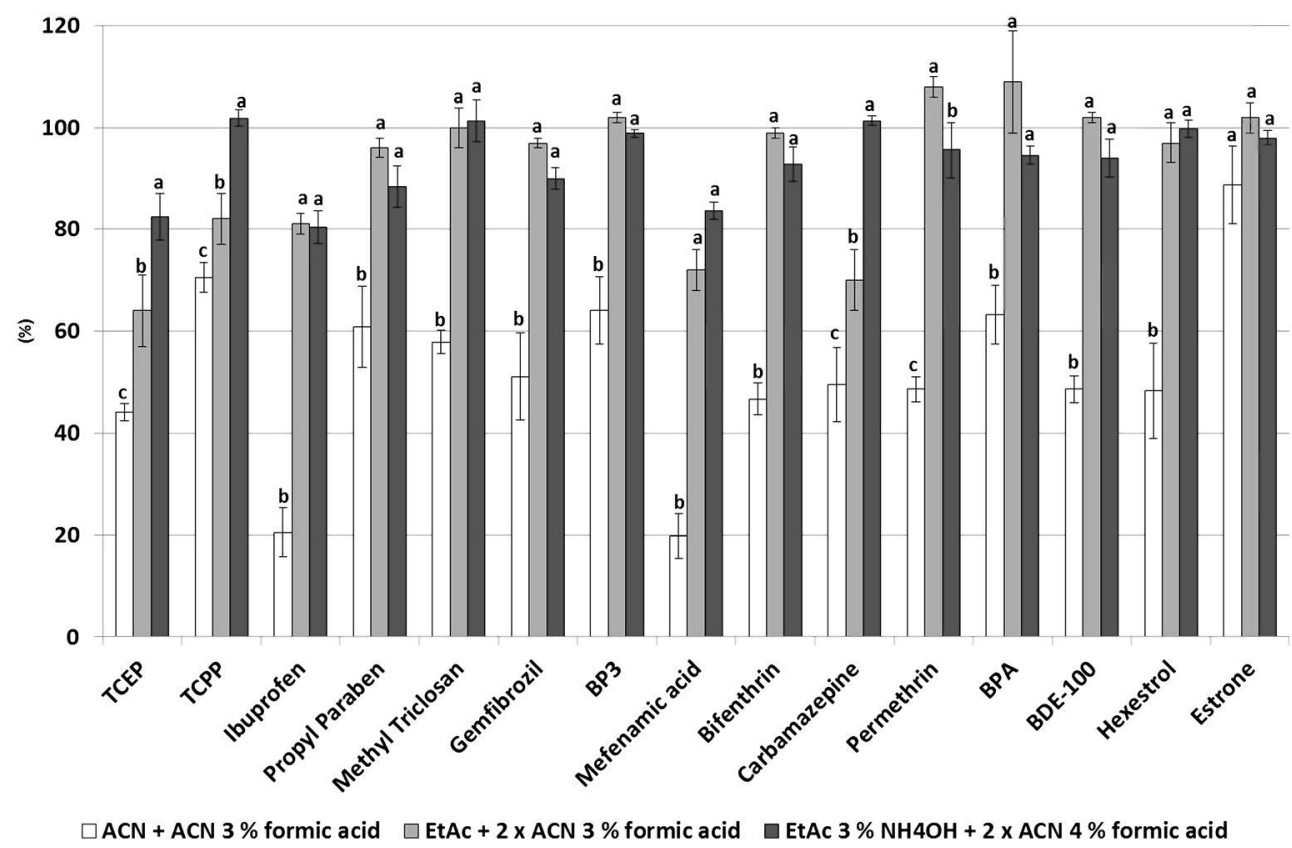

and the best recoveries were obtained with EtAc $3 \%$ $\mathrm{NH}_{4} \mathrm{OH}+2 \times \mathrm{ACN} 4 \%$ formic acid, as shown in Fig. 1 .

\section{Cleanup}

Although target analytes can be determined in the conditions indicated above, plant extracts showed high content of chlorophyll and some interference appeared during MS quantification; for these reasons a cleanup step was necessary. Dispersive solid-phase extraction (dSPE) was carried out with $1 \mathrm{~mL}$ blank extracts spiked at $100 \mathrm{ng} \mathrm{g}^{-1}$ and $0.1 \mathrm{~g}$ of sorbent. Four sorbents were tested: GCB, PSA, Chlorofiltr, and C18.
Fig. 2 Cleanup sorbent selection using Typha angustifolia spiked at $100 \mathrm{ng} \mathrm{g}^{-1}$. Different letters indicate significant differences $(p \leq 0.01)$

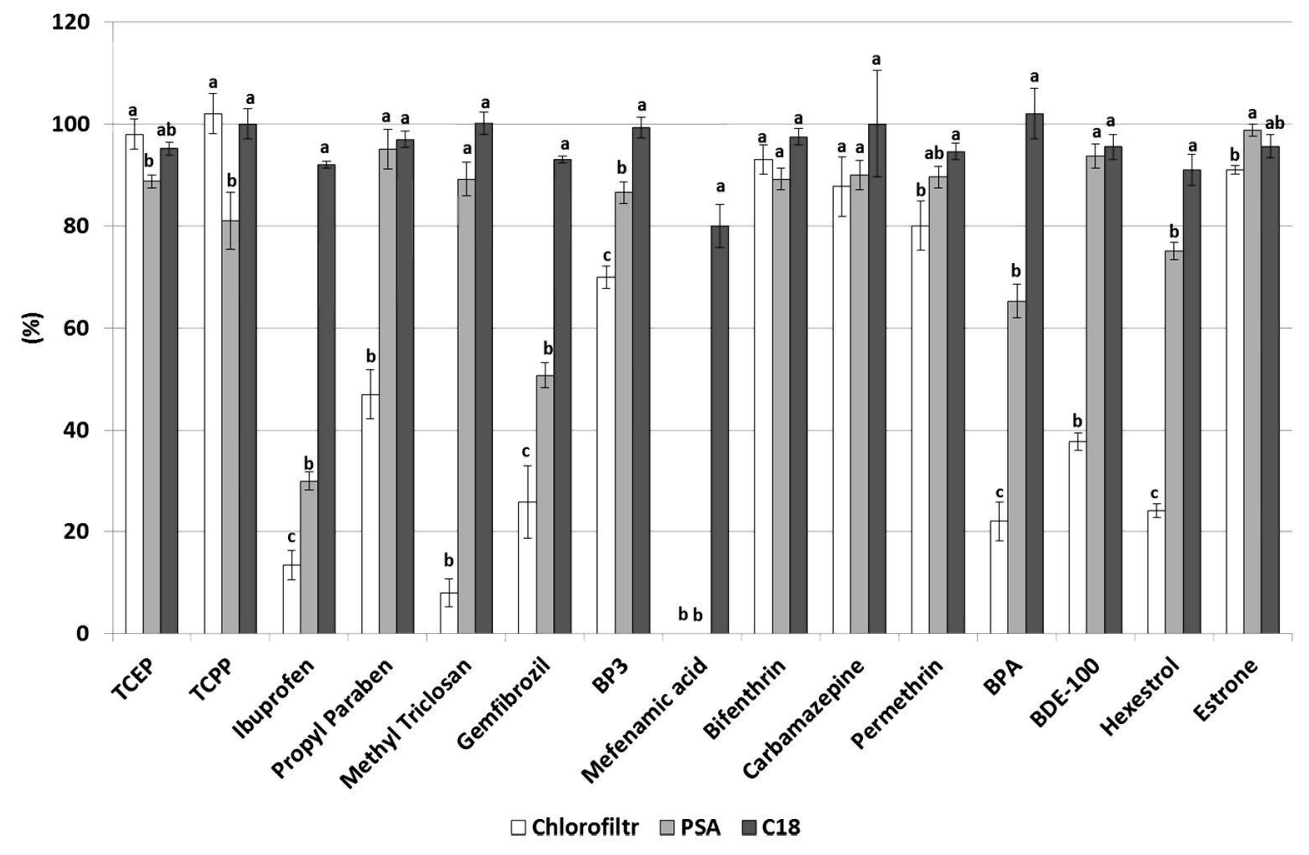


GCB showed the best performance removing chlorophylls completely, but it showed the lowest recoveries because planar compounds are retained in its surface (data not shown). PSA removes pigments and sugars, but showed the poorest removal of green pigments, and all the acidic compounds studied were not recovered at all because of the amine group of the PSA, as described by other authors (Paya et al. 2007). Recoveries using Chlorofiltr were much higher, but the extracts remained slightly green, although its main purpose is to eliminate chlorophyll. C18 showed the best performance eliminating most of the chlorophyll and other interferences with the best recoveries as shown in Fig. 2. Thus, C18 was selected as sorbent for the purification of the extracts using 5 -mL glass columns. The influence of the amount of C18 ( 0.5 , 1 , or $2 \mathrm{~g}$ ) was also studied and $0.5 \mathrm{~g}$ were not enough to remove interferences but with 1 and $2 \mathrm{~g}$, similar recoveries and removal of interferences were obtained. Therefore, the cleanup was performed with $1 \mathrm{~g}$ of $\mathrm{C} 18$.

\section{Method validation}

In order to determine the accuracy of the method, recoveries were carried out spiking four different aquatic plants at two levels, 100 and $25 \mathrm{ng} \mathrm{g}^{-1}$ (Table 2). Satisfactory recoveries were obtained with the four plants for most of the compounds. In comparison to other studies in plants (Wu et al. 2012; Winker et al. 2010), where less compounds were studied, our work showed in general better recoveries. Repeatability was evaluated by analyzing six replicates within a given day and reproducibility by determining the recoveries of six

Table 2 Recoveries ( $\%)$ and relative standard deviations ( $\operatorname{RSD}(n=4), \%$ in parenthesis) obtained for target compounds in different aquatic plants

\begin{tabular}{|c|c|c|c|c|c|c|c|c|}
\hline & \multicolumn{2}{|c|}{ Typha angustifolia } & \multicolumn{2}{|c|}{ Arundo donax } & \multicolumn{2}{|c|}{ Lemna minor } & \multicolumn{2}{|l|}{ Oryza sativa } \\
\hline & $100 \mathrm{ng} \mathrm{g}^{-1}$ & $25 \mathrm{ng} \mathrm{g}^{-1}$ & $100 \mathrm{ng} \mathrm{g}^{-1}$ & $25 \mathrm{ng} \mathrm{g}^{-1}$ & $100 \mathrm{ng} \mathrm{g}^{-1}$ & $25 \mathrm{ng} \mathrm{g}^{-1}$ & $100 \mathrm{ng} \mathrm{g}^{-1}$ & $25 \mathrm{ng} \mathrm{g}^{-1}$ \\
\hline Methyl paraben & $70(8)$ & $82(8)$ & $76(5)$ & $72(9)$ & $83(5)$ & $88(8)$ & $75(5)$ & $81(6)$ \\
\hline TCEP & $84(4)$ & $80(9)$ & $74(3)$ & $94(6)$ & $94(7)$ & $85(6)$ & $90(3)$ & $73(3)$ \\
\hline TCPP & $94(9)$ & $81(8)$ & $100(3)$ & $96(9)$ & $83(8)$ & $91(5)$ & $99(3)$ & $74(6)$ \\
\hline Ibuprofen & $100(3)$ & $71(3)$ & $70(6)$ & $72(5)$ & $75(2)$ & $73(3)$ & $120(7)$ & $112(9)$ \\
\hline Propyl paraben & $89(3)$ & $80(6)$ & $86(2)$ & $80(5)$ & $88(2)$ & $90(4)$ & $78(6)$ & $74(10)$ \\
\hline Methyl triclosan & $88(3)$ & $74(7)$ & $87(4)$ & $83(8)$ & $111(3)$ & $79(4)$ & $86(4)$ & $73(5)$ \\
\hline Gemfibrozil & $86(6)$ & $81(5)$ & $77(7)$ & $79(10)$ & $77(3)$ & $77(8)$ & $81(9)$ & $71(4)$ \\
\hline Nonylphenol & $87(2)$ & $83(8)$ & $70(2)$ & $77(5)$ & $88(3)$ & $79(4)$ & $98(2)$ & $80(3)$ \\
\hline Fenoprofen & $78(9)$ & $71(3)$ & $72(8)$ & $78(2)$ & $78(3)$ & $81(3)$ & $87(5)$ & $74(6)$ \\
\hline $\mathrm{BP} 3$ & $97(4)$ & $98(6)$ & $78(7)$ & $80(4)$ & $79(3)$ & $76(4)$ & $120(5)$ & $71(6)$ \\
\hline Naproxen & $82(8)$ & $98(2)$ & $86(3)$ & $79(5)$ & $81(4)$ & $82(9)$ & $99(3)$ & $75(2)$ \\
\hline Triclosan & $89(4)$ & $84(2)$ & $94(11)$ & $80(7)$ & $84(2)$ & $85(5)$ & $99(2)$ & $78(3)$ \\
\hline Mefenamic acid & $91(8)$ & $94(8)$ & $70(9)$ & $107(3)$ & $74(8)$ & $87(4)$ & $80(8)$ & $79(3)$ \\
\hline Ketoprofen & $73(2)$ & $120(2)$ & $75(10)$ & $98(8)$ & $72(4)$ & $100(3)$ & $98(9)$ & $73(2)$ \\
\hline Bifenthrin & $86(3)$ & $89(7)$ & $94(5)$ & $82(5)$ & $91(4)$ & $93(3)$ & $88(6)$ & $75(4)$ \\
\hline Fenpropathrin & $84(3)$ & $89(7)$ & $90(6)$ & $73(5)$ & $97(9)$ & $95(9)$ & $95(4)$ & $71(2)$ \\
\hline Carbamazepine & $90(2)$ & $83(2)$ & $88(3)$ & $75(9)$ & $98(2)$ & $96(4)$ & $85(5)$ & $79(3)$ \\
\hline BDE-47 & $76(8)$ & $84(9)$ & $89(3)$ & $82(6)$ & $86(5)$ & $88(6)$ & $90(4)$ & $74(3)$ \\
\hline Fenofibrate & $83(3)$ & $82(8)$ & $89(5)$ & $83(5)$ & $87(5)$ & $91(6)$ & $94(3)$ & $80(4)$ \\
\hline$\lambda$-Cyhalothrin & $83(11)$ & $80(5)$ & $85(6)$ & $90(11)$ & $93(6)$ & $82(7)$ & $91(3)$ & $101(8)$ \\
\hline Permethrin & $83(2)$ & $83(8)$ & $91(5)$ & $79(6)$ & $89(6)$ & $83(3)$ & $92(5)$ & $86(5)$ \\
\hline $\mathrm{BPA}$ & $77(7)$ & $77(4)$ & $107(10)$ & $105(3)$ & $80(10)$ & $80(4)$ & $97(5)$ & $70(5)$ \\
\hline BDE-100 & $86(2)$ & $80(9)$ & $88(4)$ & $79(9)$ & $86(8)$ & $87(4)$ & $91(4)$ & $86(4)$ \\
\hline Cyfluthrin & $80(4)$ & $84(7)$ & $87(5)$ & $82(8)$ & $82(9)$ & $88(7)$ & $90(7)$ & $96(6)$ \\
\hline Hexestrol & $90(0)$ & $80(7)$ & $85(3)$ & $78(6)$ & $92(2)$ & $100(2)$ & $99(2)$ & $77(4)$ \\
\hline$\alpha$-Cypermethrin & $81(3)$ & $79(8)$ & $83(4)$ & $87(10)$ & $87(8)$ & $89(7)$ & $91(3)$ & $95(8)$ \\
\hline Diethylstilbestrol & $97(6)$ & $101(2)$ & $111(4)$ & $86(6)$ & $84(3)$ & $72(3)$ & $77(2)$ & $72(3)$ \\
\hline$\tau$-Fluvalinate & $74(3)$ & $85(8)$ & $82(6)$ & $86(6)$ & $76(7)$ & $87(8)$ & $86(5)$ & $92(9)$ \\
\hline Estrone & $103(11)$ & $97(9)$ & $95(5)$ & $74(10)$ & $98(3)$ & $81(3)$ & $107(9)$ & $89(7)$ \\
\hline Esfenvalerate & $82(11)$ & $74(6)$ & $95(6)$ & $89(2)$ & $80(5)$ & $83(6)$ & $95(7)$ & $92(8)$ \\
\hline Deltamethrin & $80(5)$ & $73(11)$ & $83(7)$ & $95(7)$ & $83(6)$ & $90(7)$ & $85(8)$ & $89(5)$ \\
\hline
\end{tabular}


replicates within different days, and RSD lower than 6 and $10 \%$, respectively, was obtained.

MDLs and LOQs obtained for the different aquatic plants are shown in Table 3. MDLs ranged from 0.3 to $2.2 \mathrm{ng} \mathrm{g}^{-1}$. The differences reported were related to the background noise and the recoveries obtained in the four matrices. Low limits were achieved for all the aquatic plants, being similar to those reported by $\mathrm{Wu}$ et al. (2012) in vegetables and better than the ones published by other authors (Winker et al. 2010; Calderon-Preciado et al. 2009).

The chromatographic response of analytes may be affected by the presence of matrix components. Therefore, matrix effects were evaluated preparing two multipoint calibration curves using a set prepared with solvent-based standards and the other with matrix-matched standards. A good linearity was obtained in the range of 1 to $400 \mathrm{ng} \mathrm{g}^{-1}$, with correlation coefficients $\geq 0.994$ for all the compounds studied. The slopes obtained by plotting the seven concentration levels against response, following linear regression analysis, were compared (Fig. 3). A significant difference of the chromatographic response was observed for bifenthrin (response increase) and for carbamazepine (response suppression). On the other hand, compounds such as diethylstilbestrol were not affected by matrix components. The analysis of pharmaceuticals in neat solvent produced, in general, calibration curves with higher slopes when compared to matrix-matched standards. Hormones did not show differences and the analysis of pyrethroids in neat solvent produced calibration curves with lower slopes when compared to matrix-matched standards for most compounds. In general, an enhancement of analyte response is
Table 3 Method detection limits (MDL, $\mathrm{ng} \mathrm{g}^{-1}$ ) and limits of quantification ( $\mathrm{LOQ}, \mathrm{ng} \mathrm{g}^{-1}$ ) obtained for the analytes in the different aquatic plants studied

\begin{tabular}{|c|c|c|c|c|c|c|c|c|}
\hline & \multicolumn{2}{|c|}{ Typha angustifolia } & \multicolumn{2}{|c|}{ Arundo donax } & \multicolumn{2}{|c|}{ Lemna minor } & \multicolumn{2}{|c|}{ Oryza sativa } \\
\hline & MDL & LOQ & MDL & LOQ & MDL & LOQ & MDL & LOQ \\
\hline Methyl paraben & 0.4 & 1.2 & 0.5 & 1.7 & 0.4 & 1.5 & 0.8 & 3.0 \\
\hline TCEP & 1.5 & 3.2 & 0.5 & 1.9 & 0.6 & 2.1 & 1.2 & 4.2 \\
\hline ТСРP & 0.8 & 2.4 & 0.3 & 1.0 & 0.9 & 2.9 & 0.8 & 2.8 \\
\hline Ibuprofen & 0.8 & 2.7 & 0.7 & 2.6 & 0.8 & 2.7 & 0.8 & 2.8 \\
\hline Propyl paraben & 0.3 & 1.0 & 0.3 & 1.0 & 0.3 & 1.2 & 1.1 & 3.8 \\
\hline Methyl triclosan & 1.3 & 4.0 & 0.3 & 1.0 & 0.5 & 1.6 & 1.5 & 5.3 \\
\hline Gemfibrozil & 0.5 & 1.5 & 1.1 & 3.2 & 0.3 & 1.1 & 0.8 & 2.7 \\
\hline Nonylphenol & 0.4 & 1.5 & 1.2 & 3.8 & 1.4 & 3.8 & 0.7 & 2.5 \\
\hline Fenoprofen & 0.9 & 2.6 & 1.3 & 3.7 & 0.6 & 2.0 & 1.0 & 2.9 \\
\hline BP3 & 0.8 & 2.5 & 1.0 & 3.2 & 0.8 & 2.7 & 0.4 & 1.4 \\
\hline Naproxen & 1.0 & 3.1 & 1.0 & 3.1 & 0.7 & 2.4 & 1.0 & 3.3 \\
\hline Triclosan & 0.3 & 1.0 & 1.0 & 3.5 & 0.6 & 1.9 & 0.6 & 1.9 \\
\hline Mefenamic acid & 0.4 & 1.4 & 0.9 & 2.7 & 0.8 & 2.5 & 0.9 & 3.1 \\
\hline Ketoprofen & 0.3 & 1.0 & 1.5 & 4.8 & 1.1 & 3.2 & 2.1 & 6.3 \\
\hline Bifenthrin & 0.4 & 1.3 & 0.3 & 1.0 & 0.5 & 1.9 & 0.7 & 2.5 \\
\hline Fenpropathrin & 1.2 & 3.6 & 0.3 & 1.0 & 0.5 & 1.6 & 0.6 & 2.1 \\
\hline Carbamazepine & 0.5 & 1.5 & 0.7 & 2.4 & 0.3 & 1.1 & 0.3 & 1.0 \\
\hline BDE-47 & 0.7 & 2.5 & 1.1 & 3.8 & 0.8 & 2.6 & 0.3 & 1.0 \\
\hline Fenofibrate & 1.0 & 2.7 & 0.7 & 2.3 & 0.7 & 2.0 & 0.5 & 1.6 \\
\hline$\lambda$-Cyhalothrin & 0.9 & 3.0 & 0.8 & 2.8 & 0.9 & 3.1 & 0.8 & 2.7 \\
\hline Permethrin & 1.1 & 3.6 & 0.3 & 1.0 & 0.5 & 1.8 & 0.7 & 2.3 \\
\hline $\mathrm{BPA}$ & 1.5 & 3.2 & 1.1 & 3.4 & 0.6 & 1.9 & 0.9 & 3.0 \\
\hline $\mathrm{BDE}-100$ & 1.1 & 3.6 & 0.4 & 1.3 & 1.0 & 3.5 & 0.3 & 1.0 \\
\hline Cyfluthrin & 1.0 & 3.1 & 0.6 & 2.1 & 0.8 & 2.6 & 0.3 & 1.0 \\
\hline Hexestrol & 0.5 & 1.8 & 0.4 & 1.3 & 0.4 & 1.3 & 0.9 & 3.1 \\
\hline$\alpha$-Cypermethrin & 1.1 & 3.5 & 0.3 & 1.0 & 0.8 & 2.7 & 0.9 & 3.1 \\
\hline Diethylstilbestrol & 0.3 & 1.0 & 0.9 & 3.0 & 0.7 & 2.4 & 2.2 & 6.7 \\
\hline$\tau$-Fluvalinate & 0.9 & 2.8 & 0.6 & 2.0 & 0.6 & 2.0 & 0.4 & 1.2 \\
\hline Estrone & 0.5 & 1.8 & 0.9 & 3.1 & 0.7 & 2.5 & 0.4 & 1.2 \\
\hline Esfenvalerate & 0.6 & 2.0 & 0.8 & 2.8 & 1.1 & 3.7 & 1.4 & 4.2 \\
\hline Deltamethrin & 1.3 & 3.3 & 0.6 & 2.2 & 2.2 & 4.8 & 1.2 & 4.0 \\
\hline
\end{tabular}



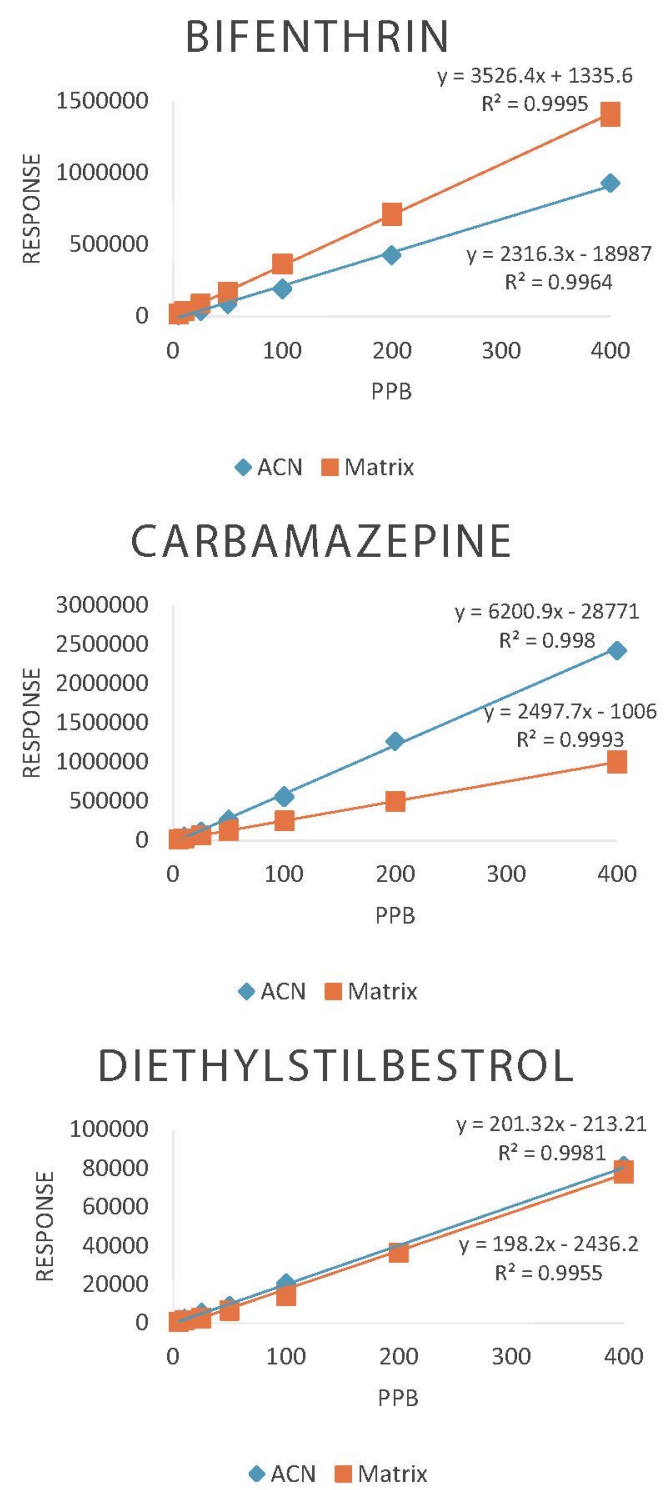

Fig. 3 Comparison of calibration curves of bifenthrin, carbamazepine, and diethylstilbestrol, obtained by injection of standards in neat solvent (diamond) and spiked plant extracts (square) observed in gas chromatography due to the presence of coextractives that may improve the transfer of some compounds, i.e., pyrethroids, by blocking active sites in the chromatographic system. On the other hand, although the derivatization step is carried out with an excess of reagent, matrix components may compete with target analytes, and thus, a lower chromatographic response is observed, as it occurs in general with pharmaceuticals. Thus, quantification was carried out using matrix-matched standards in order to overcome the matrix effects observed and have more accuracy in the quantification of samples.

\section{Analysis of real samples}

The developed analytical method was applied to different aquatic plants collected from rivers located in three Spanish regions (Valencia, Madrid, and Andalucía) in order to show the feasibility of the analytical technique to detect environmental levels of the selected contaminants in common aquatic plants of the studied area.

Table 4 shows the compounds found in the different aquatic plants analyzed. Methyl and propyl paraben, BPA, BP3, cyfluthrin, and cypermethrin were found at levels ranging from 6 to $25 \mathrm{ng} \mathrm{g}^{-1}$ wet weight, except for cypermethrin that was detected at $235 \mathrm{ng} \mathrm{g}^{-1}$ wet weight in $O$. sativa samples.

The concentration and fate of emerging contaminants in water, where several processes like adsorption, transport, and degradation are involved, affect their bioavailability to plants. In the studied area of Turia and Manzanares rivers (Valencia and Madrid, respectively), methyl and propyl paraben, BPA, triclosan, and nonylphenol were often detected in water (Carmona et al. 2014; Esteban et al. 2014). On the contrary, no residues were reported in the area of Guadalfeo river (Andalucia), which is located in a sparsely populated area with scarce industrial activity and, consequently, no residues were found in the aquatic plants from this river. Among

Table 4 Analytes detected in aquatic plants

\begin{tabular}{|c|c|c|c|c|c|c|c|}
\hline & \multicolumn{3}{|l|}{ Turia River } & \multirow{3}{*}{$\begin{array}{l}\text { Albufera Lake } \\
\text { (Valencia) } \\
\text { Oryza sativa }\end{array}$} & \multicolumn{2}{|l|}{ Manzanares River } & \multirow{3}{*}{$\begin{array}{l}\text { Guadalfeo River } \\
\text { (Andalucía) } \\
\text { Arundo donax }\end{array}$} \\
\hline & \multicolumn{3}{|l|}{ (Valencia) } & & \multicolumn{2}{|l|}{ (Madrid) } & \\
\hline & Typha angustifolia & Arundo donax & Lemna minor & & Typha angustifolia & Arundo donax & \\
\hline Methyl paraben & n.d. & n.d. & n.d. & n.d. & $12 \pm 1$ & n.d. & n.d. \\
\hline Propyl paraben & $7 \pm 1$ & n.d. & n.d. & $14 \pm 1$ & n.d. & n.d. & n.d. \\
\hline $\mathrm{BP} 3$ & $8 \pm 1$ & n.d. & n.d. & n.d. & $17 \pm 6$ & $20 \pm 2$ & n.d. \\
\hline BPA & $15 \pm 1$ & $18 \pm 3$ & $18 \pm 2$ & $25 \pm 6$ & n.d. & n.d. & n.d. \\
\hline Cyfluthrin & $6 \pm 1$ & n.d. & n.d. & n.d. & n.d. & n.d. & n.d. \\
\hline Cypermethrin & n.d. & n.d. & n.d. & $235 \pm 19$ & n.d. & n.d. & n.d. \\
\hline
\end{tabular}

Data are expressed as nanogram per gram wet weight, mean \pm SD for $n=3$

n.d not detected 
the compounds most frequently detected in water, BPA and methyl and propyl paraben, were also detected in aquatic plants, whereas triclosan and nonylphenol were not found, although they have been reported at higher levels in water from the studied area (Carmona et al. 2014; Esteban et al. 2014). A greater translocation has been reported for compounds with $\log K_{\text {ow }}$ between 1 and 3.5, whereas compounds with higher $\log K_{\text {ow }}$ tend to be not taken up (Eggen et al. 2013; García-Valcárcel et al. 2016). This may explain why triclosan and nonylphenol were not detected in the aquatic plants studied (see Table 1).

Cypermethrin was detected in O. sativa collected from Albufera (Valencia) that is fed by the Turia River. In this river, cypermethrin was found in water and fish due to the intense agricultural use of the surroundings (Ccanccapa et al. 2016; Corcellas et al. 2015).

\section{Conclusions}

A multiresidue method was developed and validated for the determination of 31 organic pollutants in aquatic plants. UAMSPD was applied to extract target compounds from T. angustifolia, A. donax, $O$. sativa, and L. minor at two levels (100 and $25 \mathrm{ng} \mathrm{g}^{-1}$ wet weight). These contaminants were determined by gas chromatography-mass spectrometry after reaction with MTBSTFA:TBDMCS to derivatize amine and hydroxyl polar groups of the target analytes. Good recoveries were obtained for most of the compounds in the four aquatic plants studied, with low limits of detection and quantification. The developed method was applied to aquatic plants collected from three rivers located in different Spanish regions to demonstrate the feasibility of the analytical technique to detect the selected contaminants in common aquatic plants at environmental levels. Six of the compounds studied were detected at concentrations ranging from 6 to $25 \mathrm{ng} \mathrm{g}^{-1}$ wet weight, except cypermethrin that was detected at $235 \mathrm{ng} \mathrm{g}^{-1}$ wet weight in $O$. sativa samples. Given the diverse physical-chemical properties of the compounds considered in the present study, this method can be used for monitoring other organic contaminants in aquatic plants. Nevertheless, further research needs to be done on the use of the developed analytical technique to assess the contamination of rivers and to better understand the role that aquatic plants may play regarding pollution mitigation in aquatic environments such as wetlands and rivers.

\footnotetext{
Acknowledgments The authors wish to thank Instituto Nacional de Investigación y Tecnología Agraria y Alimentaria for the predoctoral fellowship (R. Aznar), the Spanish Ministry of Economy and Competitiveness (RTA2014-00012-C03-01) for financial support, and Isabel Villalón for her contribution to this work.
}

\section{References}

Al Aukidy M, Verlicchi P, Jelic A, Petrovic M, Barcelo D (2012) Monitoring release of pharmaceutical compounds: occurrence and environmental risk assessment of two WWTP effluents and their receiving bodies in the Po Valley, Italy. Sci Total Environ 438:15-25

Albero B, Perez RA, Sanchez-Brunete C, Tadeo JL (2012) Occurrence and analysis of parabens in municipal sewage sludge from wastewater treatment plants in Madrid (Spain). J Hazard Mater 239:48-55

Aznar R, Albero B, Sanchez-Brunete C, Miguel E, Tadeo JL (2014a) Multiresidue analysis of insecticides and other selected environmental contaminants in poultry manure by gas chromatography-mass spectrometry. J AOAC Int 97:978-986

Aznar R, Sanchez-Brunete C, Albero B, Rodriguez JA, Tadeo JL (2014b) Occurrence and analysis of selected pharmaceutical compounds in soil from Spanish agricultural fields. Environ Sci Pollut Res 21: $4772-4782$

Bell KY, Bandy J, Finnegan BJ, Keen O, Mauter MS, Parker AM, Sima LC, Stretz HA (2013) Emerging pollutants - part II: treatment. Water Environ Res 85:2022-2071

Bhandari A, Surampalli RY, Adams CD, Champagne P, Ong SK, Tyagi RD, Zhang TC (2009) Contaminants of emerging environmental concern. American Society of Civil Engineers

Bisceglia KJ, Yu JT, Coelhan M, Bouwer EJ, Roberts AL (2010) Trace determination of pharmaceuticals and other wastewater-derived micropollutants by solid phase extraction and gas chromatography/ mass spectrometry. J Chromatogr A 1217:558-564

Calderon-Preciado D, Jimenez-Cartagena C, Penuela G, Bayona JM (2009) Development of an analytical procedure for the determination of emerging and priority organic pollutants in leafy vegetables by pressurized solvent extraction followed by GC-MS determination. Anal Bioanal Chem 394:1319-1327

Calderon-Preciado D, Matamoros V, Bayona JM (2011) Occurrence and potential crop uptake of emerging contaminants and related compounds in an agricultural irrigation network. Sci Total Environ 412: $14-19$

Carmona E, Andreu V, Pico Y (2014) Occurrence of acidic pharmaceuticals and personal care products in Tuna River Basin: from waste to drinking water. Sci Total Environ 484:53-63

Ccanccapa A, Masia A, Andreu V, Pico Y (2016) Spatio-temporal patterns of pesticide residues in the Turia and Jucar Rivers (Spain). Sci Total Environ 540:200-210

Corcellas C, Eljarrat E, Barcelo B (2015) First report of pyrethroid bioaccumulation in wild river fish: $q$ case study in Iberian river basins (Spain). Environ Int 75:110-116

Dordio AV, Belo M, Martins Teixeira D, Palace Carvalho AJ, Dias CMB, Picó Y, Pinto AP (2011a) Evaluation of carbamazepine uptake and metabolization by Typha spp., a plant with potential use in phytotreatment. Bioresour Technol 102:7827-7834

Dordio A, Ferro R, Teixeira D, Palace AJ, Pinto AP, Dias CMB (2011b) Study on the use of Typha spp. for the phytotreatment of water contaminated with ibuprofen. Int J Environ Anal Chem 91:654-667

Eggen T, Heimstad ES, Stuanes O, Norli HR (2013) Uptake and translocation of organophosphates and other emerging contaminants in food and forage crops. Environ Sci Pollut Res 20:4520-4531

Esteban S, Gorga M, Petrovic M, Gonzalez-Alonso S, Barcelo D, Valcarcel Y (2014) Analysis and occurrence of endocrinedisrupting compounds and estrogenic activity in the surface waters of Central Spain. Sci Total Environ 466:939-951

García-Valcárcel AI, Loureiro I, Escorial C, Molero E, Tadeo JL (2016) Uptake of azoles by lamb's lettuce (Valerianella locusta L.) grown in hydroponic conditions. Ecotoxicol Environ Saf 124:138-146

Goldstein M, Shenker M, Chefetz B (2014) Insights into the uptake processes of wastewater-borne pharmaceuticals by vegetables. Environ Sci Technol 48:5593-5600 
Harada A, Komori K, Nakada N, Kitamura K, Suzuki Y (2008) Biological effects of PPCPs on aquatic lives and evaluation of river waters affected by different wastewater treatment levels. Water Sci Technol 58:1541-1546

Herklotz PA, Gurung P, Heuvel BV, Kinney CA (2010) Uptake of human pharmaceuticals by plants grown under hydroponic conditions. Chemosphere 78:1416-1421

Kinney CA, Furlong ET, Werner SL, Cahill JD (2006) Presence and distribution of wastewater-derived pharmaceuticals in soil irrigated with reclaimed water. Environ Toxicol Chem 25:317-326

Kohler HR, Triebskorn R (2013) Wildlife ecotoxicology of pesticides: can we track effects to the population level and beyond? Science 341:759-765

Matamoros V, Calderon-Preciado D, Dominguez C, Bayona JM (2012) Analytical procedures for the determination of emerging organic contaminants in plant material: a review. Anal Chim Acta 722:8-20

Niewiadowska A, Kiljanek T, Semeniuk S, Zmudzki J (2010) Determination of pyrethroid residues in meat by gas chromatography with electron capture detection. Bull Vet Inst Pulawy 54:595-599

Oros DR, Werner I (2005) Pyrethroid insecticides: an analysis of use patterns, distributions, potential toxicity and fate in the Sacramento-San Joaquin Delta and Central Valley. White Paper for the Interagency

Ortiz de Garcia S, Pinto GP, Garcia-Encina PA, Mata RI (2013) Ranking of concern, based on environmental indexes, for pharmaceutical and personal care products: an application to the Spanish case. J Environ Manag 129:384-97

Paya P, Anastassiades M, Mack D, Sigalova I, Tasdelen B, Oliva J, Barba A (2007) Analysis of pesticide residues using the Quick Easy Cheap Effective Rugged and Safe (QuEChERS) pesticide multiresidue method in combination with gas and liquid chromatography and tandem mass spectrometric detection. Anal Bioanal Chem 389: $1697-1714$

Reinhold D, Vishwanathan S, Park JJ, Oh D, Saunders FM (2010) Assessment of plant-driven removal of emerging organic pollutants by duckweed. Chemosphere 80:687-692
Rodil R, Quintana JB, Concha-Grana E, Lopez-Mahia P, MuniateguiLorenzo S, Prada-Rodriguez D (2012) Emerging pollutants in sewage, surface and drinking water in Galicia (NW Spain). Chemosphere 86:1040-1049

Schummer C, Delhomme O, Appenzeller BMR, Wennig R, Millet M (2009) Comparison of MTBSTFA and BSTFA in derivatization reactions of polar compounds prior to GC/MS analysis. Talanta $77: 1473-1482$

Song Y, Kai J, Song X, Zhang W, Li L (2015) Long-term toxic effects of deltamethrin and fenvalerate in soil. J Hazard Mater 289:158-64

Tanoue R, Sato Y, Motoyama M, Nakagawa S, Shinohara R, Nomiyama K (2012) Plant uptake of pharmaceutical chemicals detected in recycled organic manure and reclaimed wastewater. J Agric Food Chem 60:10203-10211

Thomas PM, Foster GD (2005) Tracking acidic pharmaceuticals, caffeine, and triclosan through the wastewater treatment process. Environ Toxicol Chem 24:25-30

Wang JZ, Li HZ, You J (2012) Distribution and toxicity of current-use insecticides in sediment of a lake receiving waters from areas in transition to urbanization. Environ Pollut 161:128-133

Weston DP, Holmes RW, You J, Lydy MJ (2005) Aquatic toxicity due to residential use of pyrethroid insecticides. Environ Sci Technol 39. 9778-9784

Winker M, Clemens J, Reich M, Gulyas H, Otterpohl R (2010) Ryegrass uptake of carbamazepine and ibuprofen applied by urine fertilization. Sci Total Environ 408:1902-1908

Wu CX, Spongberg AL, Witter JD (2011) The uptake of pharmaceuticals and personal care products by agriculturally relevant plant species. Chim Oggi 29:54-56

Wu XQ, Conkle JL, Gan J (2012) Multi-residue determination of pharmaceutical and personal care products in vegetables. J Chromatogr A 1254:78-86

Wu X, Ernst F, Conkle JL, Gan J (2013) Comparative uptake and translocation of pharmaceutical and personal care products (PPCPs) by common vegetables. Environ Int 60:15-22 